University of Nebraska - Lincoln

DigitalCommons@University of Nebraska - Lincoln

Virology Papers

Virology, Nebraska Center for

September 2004

\title{
In Vitro Expression of Full-Length and Truncated Bovine Respiratory Syncytial Virus G Proteins and Their Antibody Responses in BALB/c Mice
}

\author{
Ryan P. Brady \\ University of Nebraska-Lincoln \\ Christina L. Topliff \\ University of Nebraska-Lincoln, ctopliff2@unl.edu \\ Clayton L. Kelling \\ University of Nebraska-Lincoln, ckelling1@Unl.edu
}

Follow this and additional works at: https://digitalcommons.unl.edu/virologypub

Part of the Virology Commons

Brady, Ryan P.; Topliff, Christina L.; and Kelling, Clayton L., "In Vitro Expression of Full-Length and Truncated Bovine Respiratory Syncytial Virus G Proteins and Their Antibody Responses in BALB/c Mice" (2004). Virology Papers. 111.

https://digitalcommons.unl.edu/virologypub/111

This Article is brought to you for free and open access by the Virology, Nebraska Center for at DigitalCommons@University of Nebraska - Lincoln. It has been accepted for inclusion in Virology Papers by an authorized administrator of DigitalCommons@University of Nebraska - Lincoln. 
Published in Vaccine 22:27-28 (September 9, 2004), pp. 3762-3768; 10.1016/j.vaccine.2004.03.020

Copyright (C) 2004 Elsevier Ltd. Used by permission. http://www.sciencedirect.com/science/journal/0264410X

A contribution of the University of Nebraska Agricultural Research Division, Lincoln, NE 68583, USA. Journal Series No. 14293.

Submitted October 3, 2003; revised February 16, 2004; accepted March 1, 2004; published online April 7, 2004.

\title{
In Vitro Expression of Full-Length and Truncated Bovine Respiratory Syncytial Virus G Proteins and Their Antibody Responses in BALB/c Mice
}

\author{
Ryan P. Brady, Christina L. Topliff, and Clayton L. Kelling \\ Department of Veterinary and Biomedical Sciences, University of Nebraska, \\ East Campus Loop and Fair Street, Veterinary Basic Science, Lincoln, NE 68583-0905, USA \\ Corresponding author-C. L. Kelling, tel 402 472-3040, fax 402 472-9690, email ckelling1@unl.edu
}

\begin{abstract}
Bovine respiratory syncytial virus (BRSV) is a primary cause of lower respiratory tract disease in calves. Protection is incomplete following vaccination or natural infection, as re-infections are common. The objectives of this study were to create plasmid DNA constructs encoding the full-length, secreted, or conserved region of the BRSV G glycoprotein, and to compare and evaluate their expression in cell culture and potential to induce antibody responses in BALB/c mice. Transfection of COS-7 cells with plasmid DNA resulted in expression of the BRSV G region from each of the plasmid DNA constructs. Following inoculation of BALB/c mice with plasmid DNA, a significant and equivalent anti-BRSV G IgG response was elicited to the full-length and truncated BRSV G proteins. These constructs may be used to study host pathological and immunological responses.
\end{abstract}

Keywords: Bovine respiratory syncytial virus, DNA vaccine, Attachment glycoprotein

\section{Introduction}

Bovine respiratory syncytial virus (BRSV), an economically important respiratory pathogen in calves, is a primary cause of lower respiratory tract disease, and is an etiologic component of the bovine respiratory disease complex. Several BRSV vaccines are commercially available; however, protection is incomplete following vaccination or natural infection, as re-infections are common [1]. BRSV is closely related to human respiratory syncytial virus (HRSV), yet is antigenically distinct. The attachment $(\mathrm{G})$ glycoprotein of BRSV, which facilitates viral attachment to the host cell, is a major protective antigen, capable of inducing virus-neutralizing $(\mathrm{VN})$ antibodies [2 and 3]. Two forms of BRSV G are synthesized, based on initiation at one of two methionyl codons: a full-length, type II integral membrane protein and a truncated form which undergoes proteolytic cleavage and is secreted [4]. The BRSV G ectodomain, heavily glycosylated with O-linked sugars, is characteristically similar to mucins, which are host glycoproteins found in protective barriers. As a result, the glycosylation of the BRSV G protein may protect the viral protein from being recognized as a foreign antigen [5]. Within the mucin-like ectodomain of BRSV G exists a region spanning amino acids 166-186, that was fully-conserved among nine BRSV isolates studied [6]. This conserved region contains four cysteine residues, which are disulfide-linked, forming a characteristic "cysteine noose" that may serve to stabilize the area and be critical for receptor binding [7]. Bastien et al. , identified a synthetic peptide corresponding to this conserved region that was able to induce significant BRSV-specific antibodies in calves and was capable of preventing BRSV-associated pneumonia in the natural host [8].

Much of what is known regarding host responses to the G glycoprotein stems from the formalin-inactivated (FI)-RSV vaccine trials that not only failed to elicit protection, but also led to an exacerbated disease in vaccinated children, following natural exposure $[9,10]$. The vaccine-enhanced disease associated with FI-RSV was the result of an imbalanced T helper 2 (Th2) immune response, specifically attributed to the G glycoprotein [1118]. This biased response may be due to the failure of the 
G protein to evoke a cytotoxic T lymphocyte (CTL) response. Moreover, the secreted form of the BRSV G protein has also been linked to a Th2-biased immune response [19-21].

A number of approaches have been implemented to circumvent the shortcomings associated with the FIRSV vaccine. In particular, DNA vaccination is a novel method for eliciting an antigen-specific immune response. DNA vaccination is advantageous in that plasmid DNA vaccines can be readily developed within the laboratory. Also, DNA vaccines can induce lasting immunity and have the capability of redirecting the pattern of the immune response [22].

Immunization of mice with plasmid DNA encoding the HRSV F protein induced virus-neutralizing antibodies, CTLs, high levels of interferon- $\gamma($ IFN- $\gamma)$, and protection against infection following viral challenge [23, 24]. Moreover, immunization of mice with plasmid DNA encoding full-length or secreted HRSV G resulted in a balanced Th1/Th2 response following virus challenge, similar to that observed during a natural infection [25, 26]. DNA encoding HRSV G induced virus-neutralizing antibodies, substantial IFN- $\gamma$, lower yields of interleukin4 (IL-4) and IL-5, an absence of lung lesions when compared to FI-RSV immunization, and protection against viral replication. Even when the immune response was biased towards a Th2-like pattern, by co-administration of DNA-IL-4 with DNA-G, there was still a reduction in viral titers, and an absence of lung eosinophilia following virus challenge [27].

Earlier studies demonstrated the ability of plasmid DNA encoding BRSV G to elicit a significant BRSV Gspecific antibody response in calves [28]; however, these studies did not compare the ability of secreted or conserved BRSV G to evoke an antibody response. The objectives of this study were to create plasmid DNA constructs encoding the full-length, secreted, or conserved region of the BRSV G glycoprotein, and to compare and evaluate their expression in cell culture and their ability to induce antibody responses in BALB/c mice. In this paper, we report the ability of these plasmid constructs to be expressed in cell culture and to elicit a significant and equivalent anti-BRSV G IgG response in BALB/c mice.

\section{Materials and methods}

\subsection{Cells and viruses}

Bovine turbinate (BT) cells (National Veterinary Services Laboratory, Ames, IA) were grown in Dulbecco's Modified Eagle Medium (DMEM) supplemented with 10\% equine serum (HyClone, Logan, UT), and maintained in a $37^{\circ} \mathrm{C}$ humidified chamber with $5 \% \mathrm{CO}_{2}$. Confluent monolayers were infected with plaque-purified BRSV strain 375 at a multiplicity of infection (m.o.i.) of 0.01 in tissue culture flasks, and maintained at $33^{\circ} \mathrm{C}$ in a humid- ified chamber with $5 \% \mathrm{CO}_{2}(\sim 2$ weeks) until the cells demonstrated $50 \%$ cytopathic effect (CPE). The flasks were then frozen at $-80^{\circ} \mathrm{C}$, thawed, aliquoted, then frozen again at $-80^{\circ} \mathrm{C}$ until used.

\subsection{Construction of plasmid DNA vector encoding the full- length BRSV G glycoprotein}

BRSV 375 was propagated in BT cells and RNA was extracted according to manufacturer's instructions using TRIZOL LS reagent (Invitrogen, Carlsbad, CA). The 794 bp BRSV G glycoprotein cDNA sequence was generated from total RNA using Superscript II reverse transcriptase (Invitrogen) and the primer G2, 5'-GGTGGGATCCTAGATCTGTGTAGTTGATTGA-3', complementary to nucleotides 753-774 of the BRSV 375 G glycoprotein, with a BamHI restriction site incorporated (underlined). The BRSV G cDNA was amplified using Taq polymerase (Invitrogen), with primers G2 and G1, 5'-CAAAGGATCCTATGTCCAACCATACCCATCAT3', corresponding to nucleotides 1-21 of BRSV G. BRSV G-specific primers were purchased from Sigma Genosys (Woodlands, TX). The reaction mixture was denatured at $94{ }^{\circ} \mathrm{C}$ for $1 \mathrm{~min}$, annealed at $59^{\circ} \mathrm{C}$ for $1 \mathrm{~min}$, and extended at $72{ }^{\circ} \mathrm{C}$ for $2 \mathrm{~min}$ for a total of 30 cycles, followed by an additional extension of $7 \mathrm{~min}$ at $72{ }^{\circ} \mathrm{C}$.

The BRSV G PCR product was gel purified (QIAEX II Gel Extraction Kit, QIAGEN, Chatsworth, CA) and subcloned into pCR 2.1 vector using the TA Cloning Kit (Invitrogen). The BRSV G cDNA was excised from pCR2.1 with SpeI and EcoRV and ligated using T4 DNA ligase into the mammalian expression vector, pcDNA 3.1/His (Invitrogen), digested with EcoRV and XbaI. This procedure placed the full-length BRSV G cDNA downstream of the T7 RNA polymerase and human cytomegalovirus immediate-early promoter/enhancer and upstream of the bovine growth hormone polyadenylation signal sequence. DNA sequencing (DNA Sequencing Facility, Iowa State University, Ames, IA) was performed following cloning to verify the orientation and reading frame of the insert.

\subsection{Construction of plasmid DNA vectors encoding secreted and conserved BRSV G}

To amplify secreted and conserved BRSV G, PCR was performed on the pcDNA 3.1/His construct encoding the $794 \mathrm{bp}$ full-length BRSV G cDNA sequence using the parameters previously described. Primers G2 and SG1, 5'-GGGCACAGGATCCGCAATGATAACC-3', corresponding to nucleotides 129-150, were used to amplify secreted BRSV G (657 bp). The $85 \mathrm{bp}$ conserved region of BRSV G was amplified using primers CG2, 5'-ATGGATCCAGCAGAGTGATAAGCAAGC-3', complementary to nucleotides 541-558 and CG1, 5'-CACAGGATCCGCGCAAACACTC-3', corresponding to nucleotides 484504. Gel purified secreted and conserved BRSV G cDNA were inserted into pCR 2.1 vector, respectively, using 
the TA Cloning Kit. The secreted BRSV G region was excised from pCR2.1 with SpeI and EcoRV and ligated using T4 DNA ligase into pcDNA 3.1/His, digested with EcoRV and XbaI. Likewise, conserved BRSV G was excised from pCR 2.1 with SpeI and ApaI and ligated into pcDNA 3.1/His, digested with ApaI and XbaI, followed by DNA sequencing.

\subsection{Expression of BRSV G constructs in mammalian cells}

Expression of the recombinant BRSV G glycoproteins was evaluated in African green monkey kidney (COS-7) cells (American Type Culture Collection, Rockville, MD) following transfection using a vaccinia virus-T7 RNA polymerase expression system [29]. The T7-vaccinia virus was kindly provided by Dr. Bernard Moss, National Institutes of Health, Bethesda, MD. Following infection with T7-vaccinia virus, the COS-7 cells were transfected with plasmid DNA according to the manufacturer's instructions using a cationic lipid-mediated method (Lipofectamine 2000 Reagent, Invitrogen).

Twenty-four hours following the start of transfection, the COS-7 cells were fixed in $20 \%$ acetone (v/v) in phosphate buffered saline (PBS) and BRSV G detected using an immunoperoxidase staining protocol [30]. BRSV G protein was detected with the monoclonal antibody MAb 57 , specific for the central conserved cysteine-rich region of BRSV G [31] (kindly provided by Dr. Geraldine Taylor, Institute for Animal Health, Compton, UK), or polyclonal anti-BRSV serum as the primary antibody and biotinylated horse anti-mouse or goat anti-bovine IgG $(\mathrm{H}+\mathrm{L})$ (Vector Laboratories, Burlingame, CA), respectively, as the secondary antibody. Antibody binding was detected using streptavidin horseradish peroxidase conjugate (Zymed, San Francisco, CA) and 3-amino-9-ethyl-carbazole substrate (Sigma, St. Louis, MO). Additionally, transfected cells were lysed using $0.5 \%$ NP-40 lysis buffer, then proteins separated by discontinuous SDS-PAGE electrophoresis. The separated proteins were transferred onto a nitrocellulose membrane and non-specific sites blocked in $5 \%$ nonfat dry milk. The membrane was then incubated with the primary antibody, MAb 57 (1:1000), followed by alkaline phosphatase-labeled goat anti-mouse IgG $(\mathrm{H}+\mathrm{L})$ (KPL, Gaithersburg, MD) as the secondary antibody. Antibody binding was detected using 5-bromo-4-chloro-3indolyl-phosphate/nitroblue tetrazolium substrate (KPL, Gaithersburg, MD).

\subsection{DNA inoculation of $B A L B / c$ mice}

Plasmid DNA encoding the full-length, secreted and conserved BRSV G glycoprotein was purified using the plasmid Mega kit from QIAGEN according to the manufacturer's instructions and resuspended in $0.89 \%$ $\mathrm{NaCl}$. Four-week old, female, specific pathogen-free BALB/c mice, purchased from Charles River Laboratories (Wilmington, MA), were housed in BL-2 rooms at the Animal Research Facility, University of Nebraska, Lincoln.

Mice were assigned to one of four treatment groups: (1) pcDNA 3.1/His/full-length BRSV G (DNA-G); (2) pcDNA 3.1/His/secreted BRSV G (DNA-SG); (3) pcDNA 3.1/His/conserved BRSV G (DNA-CG); or (4) pcDNA 3.1/His/Lac Z (DNA-Lac Z). DNA-Lac Z served as a negative control for the experimental design. Each treatment group was comprised of five mice. Mice were inoculated intramuscularly (IM), in the hind leg, with $50 \mu \mathrm{g}$ of plasmid DNA. The mice were given a booster inoculation at 4, 8, 12 and 17 weeks by the same route and with the same dose of plasmid DNA. Four weeks following the final inoculation, mice were anesthetized with $40 \mu \mathrm{g} / \mathrm{g}$ ketamine and $6 \mu \mathrm{g} / \mathrm{g}$ xylazine and bled by cardiac puncture. An equal amount of Alsever's solution was added to the collected blood. The mice were then euthanatized by $\mathrm{CO}_{2}$ inhalation.

\subsection{Antibody response in mice following plasmid DNA inoculation}

Plasma was analyzed for anti-BRSV G antibodies using an indirect enzyme-linked immunosorbent assay (ELISA) protocol described by Tripp et al. 1999 [32] with modifications. The antigen used for the ELISA consisted of BT cells infected with BRSV using an m.o.i. of 0.1 or non-infected cells. Four days following infection, the cells were fixed in $20 \%$ acetone in PBS (v/v). Two-fold dilutions of mouse plasma were prepared and added to the cells in $100 \mu \mathrm{l}$ volumes. The plates were incubated at $37^{\circ} \mathrm{C}$ for $1 \mathrm{~h}$, followed by addition of goat anti-mouse IgG $(\mathrm{H}+\mathrm{L})$ conjugated to alkaline phosphatase $(1: 1000)$ (KPL, Gaithersburg, MD) for an additional hour at $37^{\circ} \mathrm{C}$. The substrate, $p$-nitrophenyl phosphate, was then added and the optical density (OD) values were determined at $410 \mathrm{~nm}$ using a microplate reader (MR 700, Dynatech Laboratories).

\subsection{Detection of virus-neutralizing antibodies}

For the detection of virus-neutralizing antibodies, twofold serial dilutions of heat-inactivated plasma $\left(56^{\circ} \mathrm{C}\right.$ for $30 \mathrm{~min})$ were made and combined with BRSV (100-200 $\left.\mathrm{TCID}_{50} / 50 \mu \mathrm{l}\right)$ for $1 \mathrm{~h}$ at $37^{\circ} \mathrm{C}$, with $5 \% \mathrm{CO}_{2}$. The virusplasma mixtures were then tested for residual $\mathrm{CPE}$ in cultures of BT cells [33]. Monolayers were examined microscopically for viral CPE 4-7 days following infection and virus-neutralizing antibody titers were expressed as the highest plasma dilution inhibiting CPE of BRSV.

\subsection{Statistical analysis}

Results in the different treatment groups of mice were compared and analyzed statistically using a two-sample Student's $t$-test. $P$-values of $<0.05$ were considered to be statistically significant. Results were presented as mean \pm S.E.M. 


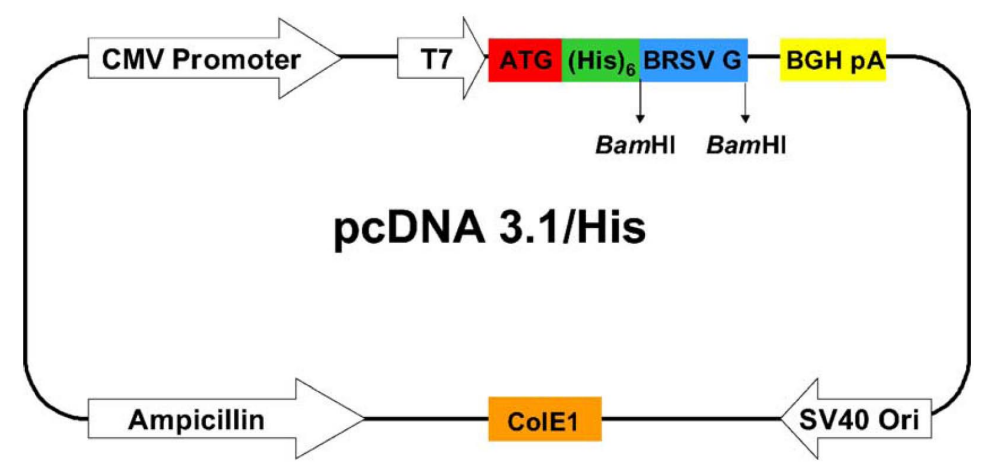

Figure 1. Schematic diagram of the pcDNA3.1/His expression vector encoding the BRSV full-length, secreted, or conserved G glycoprotein. The pcDNA 3.1/His backbone was approximately $5.5 \mathrm{~Kb}$ in length. Transcription was under the control of the CMV immediate-early promoter, or T7 promoter when using a T7 vaccinia virus expression system. An ampicillin resistance gene was included for propagation of plasmids in E. coli under ampicillin selection. BamHI restriction sites were incorporated within the forward and reverse BRSV G primers for verification of the insert.

\section{Results}

\subsection{Plasmid DNA vectors for in vitro and in vivo analysis}

The three different plasmid vectors for DNA inoculation were constructed. Agarose gel electrophoresis verified inserts of the appropriate size following restriction endonuclease digestion and DNA sequencing confirmed that the inserts were in the correct orientation, as well as in the proper reading frame (data not shown). The vectors encoded: (1) the full-length BRSV G protein; (2) a truncated BRSV G protein which is secreted; or (3) a central, fully-conserved region of the BRSV G protein (Figure 1). Using a vaccinia virus/T7 expression system, transcription was under the control of the vaccinia/T7 promoter, and the ampicillin-resistance gene, included in the vector, enabled selection in Escherichia coli.

\subsection{COS-7 cells express the recombinant BRSV G glycoproteins}

Expression was evaluated using an immunoperoxidase assay. Widespread, intracellular cytoplasmic staining was detectable in COS-7 cells transfected with plasmid DNA vectors encoding full-length, secreted, or conserved BRSV G (Figure 2). The level of intracellular cytoplasmic staining was equivalent in distribution and intensity among the three recombinants, and similar in intensity to BRSV-infected cells. As a negative control, COS-7 cells were transfected with the plasmid DNA backbone and no intracellular cytoplasmic staining was observed.

Based on Western blot analyses of lysates from COS-7 cells transfected with plasmid DNA encoding the BRSV $G$ proteins, the BRSV full-length and secreted G recombinants expressed proteins (Figure 3). Lysates collected
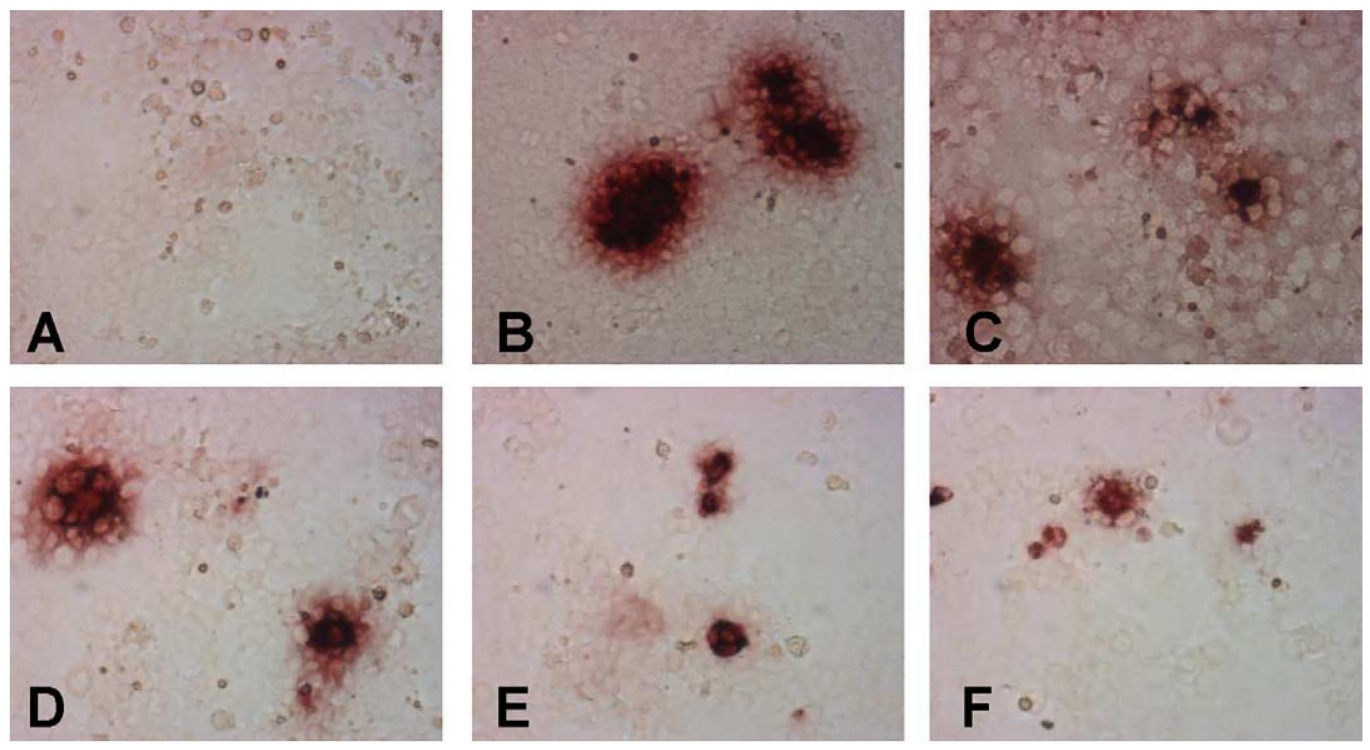

Figure 2. Intracellular cytoplasmic staining using an immunoperoxidase assay in COS-7 cells transiently transfected with plasmid DNA encoding full-length, secreted (SG), or conserved (CG) BRSV G. (A) COS-7 cells transfected with the plasmid DNA backbone. (B) BRSV-infected COS-7 cells detected with MAb 57, specific for BRSV G. (C) COS-7 cells transfected with DNA-G and detected with polyclonal anti-BRSV serum. COS-7 cells transfected with DNA-G (D), DNA-SG (E), and DNA-CG (F), and detected with MAb 57. 


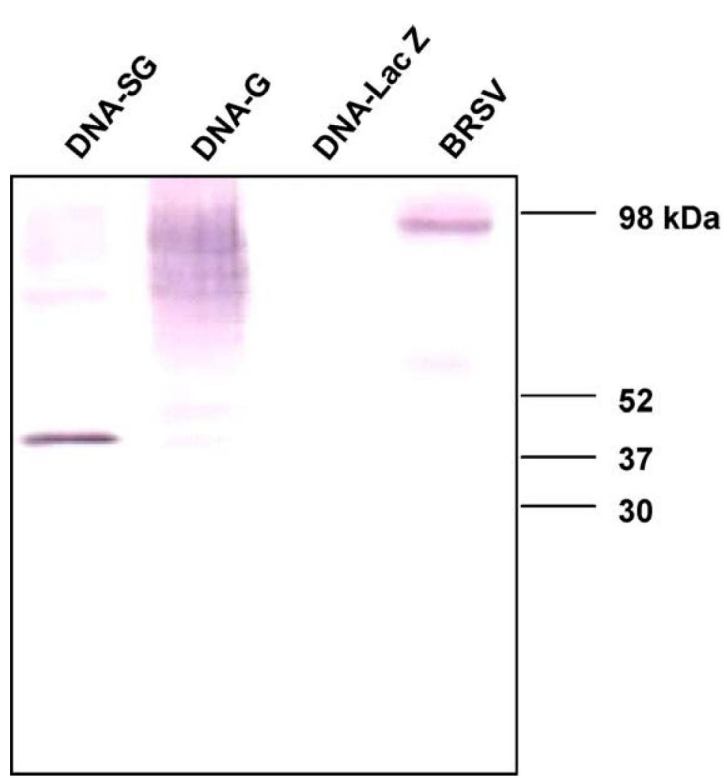

Figure 3. COS-7 cells transfected with DNA-SG and DNA-G expressing the BRSV G glycoprotein. The lysates of transfected COS-7 cells were analyzed for expression of the BRSV G glycoprotein by Western blot analyses using a BRSV G-specific monoclonal antibody (MAb 57). Lysate collected from COS-7 cells transfected with the plasmid DNA encoding a Lac Z gene (DNA-Lac Z) was used as a negative control. BRSV-infected COS-7 cell lysate was used a positive control.

from BRSV-infected COS-7 cells and from COS-7 cells transfected with the plasmid DNA backbone were used as positive and negative controls, respectively. The fulllength BRSV G recombinant resolved as several bands of similar intensity ranging in size from 70 to $90 \mathrm{kDa}$, equivalent in size to the band in the positive control lane. In contrast, the secreted BRSV G recombinant expressed primarily as a protein near $45 \mathrm{kDa}$, with a faint band resolving slightly lower than the full-length protein. Expression of the conserved BRSV G recombinant was not detectable by Western blot analysis (data not shown).

\subsection{Anti-BRSV G IgG response following plasmid DNA inoculation}

To evaluate the antibody response to the BRSV G recombinant proteins, plasma samples from mice inoculated with plasmid DNA encoding the BRSV G full-length and truncated proteins were used in an indirect ELISA and analyzed for antibodies using BRSV-infected and noninfected BT cells as antigen. Specifically, the ratio of the $\mathrm{OD}_{410 \mathrm{~nm}}$ values obtained from BRSV-infected cells to $\mathrm{OD}_{410 \mathrm{~nm}}$ values obtained from non-infected cells were plotted at each dilution of plasma (Figure 4). Based on these results, BRSV G-specific IgG antibody titers were approximately 1:80 for DNA-G, DNA-SG, and DNACG. Plasma from mice infected with live BRSV was used as a positive control for ELISA. The described ra-

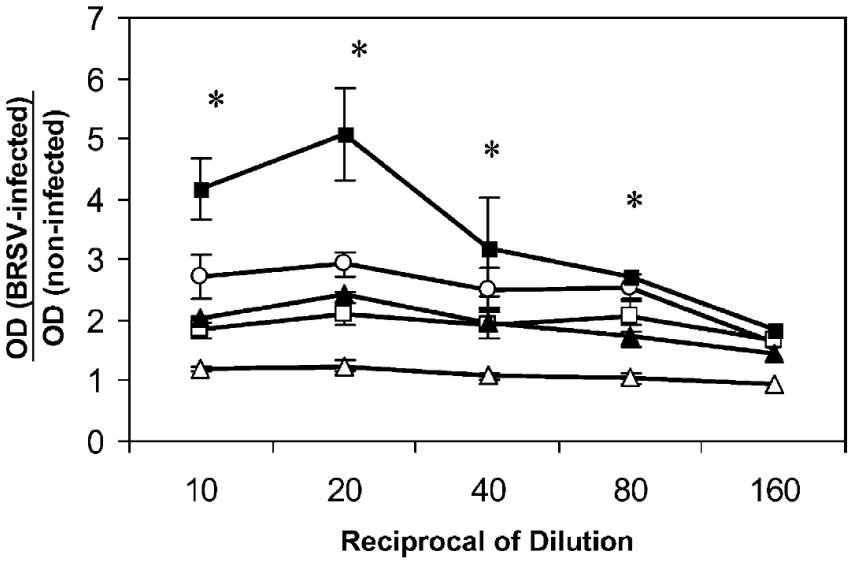

Figure 4. Anti-BRSV G IgG antibody responses in BALB/c mice following inoculation with DNA-G (open circle), DNA-SG (closed triangle), DNA-CG (open square), DNA-Lac Z (open triangle), or with live BRSV (closed square). An indirect ELISA was used to evaluate the antibody response to the plasmid DNA encoding the BRSV G full-length and truncated proteins. Optical density $(\mathrm{OD})_{410 \mathrm{~nm}}$ values from plates using BRSV-infected BT cells as antigen were compared against $\mathrm{OD}_{410 \mathrm{~nm}}$ values of plates using non-infected cells as antigen, and the mean ratios plotted at each dilution \pm S.E.M. $\left({ }^{*} P<0.05\right.$ vs. DNA-Lac $\mathrm{Z}$ inoculated mice).

tios for BRSV-infected mice were greater than the ratios for DNA-inoculated mice. As a negative control, plasma samples obtained from mice inoculated with DNA-Lac Z were analyzed by ELISA. There was not a detectable antibody response in DNA-Lac Z inoculated mice, based on the described ratios, as they remained at a baseline level at each dilution.

\subsection{DNA encoding the BRSV G full-length and truncated proteins did not induce virus-neutralizing antibodies}

Following plasmid DNA inoculation of BALB/c mice, plasma was analyzed for neutralizing antibodies against BRSV. Inoculation with plasmid DNA encoding the BRSV G full-length and truncated proteins did not lead to a marked virus-neutralizing antibody response, as the mean VN titer was $<4$, based on inhibition of CPE in BRSV-infected BT cells (data not shown).

\section{Discussion}

In this study, plasmid DNA vectors encoding the fulllength, secreted and conserved regions of the BRSV G glycoprotein were constructed for DNA immunization to evaluate their expression in cell culture and potential to induce antibody responses in BALB/c mice. All three plasmid vectors were efficiently expressed in transfected COS-7 cells. To our knowledge, this is the first report of a 
study comparing expression and immunogenicity of the full-length, secreted, and conserved regions of the BRSV $G$ glycoprotein using a plasmid DNA vaccine. DNA vaccination has been described using a number of infectious agents, such as HIV [34], and has been shown to elicit protection against a number of virulent pathogens, including Hepatitis B virus [35]. We evaluated the G glycoprotein of BRSV in a plasmid DNA vaccine, as it is a major protective antigen that has also been linked to immune-mediated enhanced disease. As a result, the availability of these DNA vaccines will permit studies of the immune response specific to the BRSV G glycoprotein, and may prove useful for studies aimed at gaining a better understanding of the pathogenesis of BRSV respiratory disease.

Analysis of the recombinant proteins in transfected COS-7 cells by an immunoperoxidase assay demonstrated that the expression of these constructs encoding the full-length, truncated and conserved regions of BRSV G was comparable among the groups and similar to that of the wild-type protein. Additionally, expression of plasmid DNA encoding full-length or secreted BRSV $G$ in transfected COS-7 cells was evaluated by Western blot analyses. The full-length BRSV G protein resolved as several bands of equivalent intensity between 70 and $90 \mathrm{kDa}$, consistent with previous findings demonstrating that the G glycoprotein of BRSV migrates as a broad band near $80-90 \mathrm{kDa}[36,37]$. The migration patterns observed may be due to the accumulation of less-glycosylated forms of the $\mathrm{G}$ glycoprotein in the transfected cells, as less-glycosylated forms of $G$ accumulate in substantial quantity [36, 37]. The secreted BRSV G protein accumulated mainly as an intense band near $45 \mathrm{kDa}$, with a faint band resolving slightly lower than the full-length protein. This pronounced band near $45 \mathrm{kDa}$ is likely a BRSV G precursor, incompletely glycosylated, with only N-linked sugars [37]. The conserved region of the BRSV G glycoprotein was not detected by Western blot analysis due to lesser sensitivity of this procedure compared to the immunoperoxidase procedure.

Production of anti-BRSV G IgG antibody titers of approximately 1:80 in mice following immunization with the three constructs, as determined by ELISA, were consistent with previous findings following plasmid DNA immunization of mice encoding HRSV G, where HRSVspecific IgG titers were $\geq 1: 64$ [30]. Similarly, others have demonstrated a detectable anti-HRSV G IgG response in BALB/c mice following plasmid DNA immunization [24-27]. The anti-BRSV G IgG titers (1:80) were similar among each of the three treatment groups (i.e. DNA-G, DNA-SG, and DNA-CG).

In summary, plasmid DNA constructs encoding the full-length, secreted, or conserved region of BRSV G were expressed equally in transfected COS-7 cells. Additionally, following inoculation of BALB/c mice with plasmid DNA encoding the full-length, secreted, or con- served BRSV G glycoprotein, a significant and comparable anti-BRSV G IgG response was elicited with each of the three constructs. Future studies involving the immunization of the natural host with plasmid DNA encoding the full-length, secreted and conserved regions of the BRSV G glycoprotein will provide information regarding protective immunity against challenge exposure.

\section{References}

1. J.C. Baker, J.A. Ellis and E.G. Clark, Bovine respiratory syncytial virus. Vet. Clin. N. Am. Food Anim. Pract. 13 (1997), pp. 425-454.

2. G. Taylor, L.H. Thomas, J.M. Furze, R.S. Cook, S.G. Wyld, R. Lerch et al., Recombinant vaccinia viruses expressing the F, $\mathrm{G}$, or $\mathrm{N}$, but not the $\mathrm{M} 2$, protein of bovine respiratory syncytial virus (BRSV) induce resistance to BRSV challenge in the calf and protect against the development of pneumonic lesions. J. Gen. Virol. 78 (1997), pp. 3195-3206.

3. S. Levine, R. Klaiber-Franco and P.R. Paradiso, Demonstration that glycoprotein $\mathrm{G}$ is the attachment protein of respiratory syncytial virus. J. Gen. Virol. 68 (1987), pp. 2521-2524.

4. S.R. Roberts, D. Lichtenstein, L.A. Ball and G.W. Wertz, The membrane-associated and secreted forms of the respiratory syncytial virus attachment glycoprotein $\mathrm{G}$ are synthesized from alternative initiation codons. J. Virol. 68 (1994), pp. 4538-4546.

5. G.W. Wertz, P.L. Collins, Y. Huang, C. Gruber, S. Levine and L.A. Ball, Nucleotide sequence of the $\mathrm{G}$ protein gene of human respiratory syncytial reveals an unusual type of viral membrane protein. Proc. Natl. Acad. Sci. U.S.A. 82 (1985), pp. 4075-4079.

6. L.C. Stine, D.K. Hoppe and C.L. Kelling, Sequence conservation in the attachment glycoprotein and antigenic diversity among bovine respiratory syncytial virus isolates. Vet. Microbiol. 54 (1997), pp. 201-221.

7. P.R. Johnson, M.K. Spriggs, R.A. Olmsted and P.L. Collins, The G glycoprotein of human respiratory syncytial viruses of subgroups A and B: extensive sequence divergence between antigenically related proteins. Proc. Natl. Acad. Sci. U.S.A. 84 (1987), pp. 5625-5629.

8. N. Bastien, G. Taylor, L.H. Thomas, S.G. Wyld, C. Simard and M. Trudel, Immunization with a peptide derived from the G glycoprotein of bovine respiratory syncytial virus (BRSV) reduces the incidence of BRSV-associated pneumonia in the natural host. Vaccine 15 (1997), pp. 1385-1390.

9. A.Z. Kapikian, R.H. Mitchell, R.M. Chanock, R.A. Shvedoff and C.E. Stewart, An epidemiologic study of altered clinical reactivity to respiratory syncytial (RS) virus infection in children previously vaccinated with an inactivated RS virus vaccine. Am. J. Epidemiol. 89 (1969), pp. 405-421.

10. H.W. Kim, J.G. Canchola, C.D. Brandt, G. Pyles, R.M. Chanock, K. Jensen et al., Respiratory syncytial virus disease in infants despite prior administration of antigenic inactivated vaccine. Am. J. Epidemiol. 89 (1969), pp. 422-434.

11. M. Connors, A.B. Kulkarni, C.-Y. Firestone, K.L. Holmes, H.C. Morse, III, A.V. Sotnikov et al., Pulmonary histopathology induced by respiratory syncytial virus (RSV) chal- 
lenge of formalin-inactivated RSV-immunized BALB/c mice is abrogated by depletion of CD4+ T cells. J. Virol. 66 (1992), pp. 7444-7451.

12. B.S. Graham, G.S. Henderson, Y.-W. Tang, X. Lu, K.M. Neuzil and D.G. Colley, Priming immunization determines $\mathrm{T}$ helper cytokine mRNA expression patterns in lungs of mice challenged with respiratory syncytial virus. J. Immunol. 151 (1993), pp. 2032-2040.

13. M.E. Waris, C. Tsou, D.D. Erdman, S.R. Zaki and L.J. Anderson, Respiratory syncytial virus infection in BALB/c mice previously immunized with formalin-inactivated virus induces enhanced pulmonary inflammatory response with a predominant Th2-like cytokine pattern. J. Virol. 70 (1996), pp. 2852-2860.

14. P.J.M. Openshaw, S.L. Clarke and F.M. Record, Pulmonary eosinophilic response to respiratory syncytial virus infection in mice sensitized to the major surface glycoprotein G. Int. Immunol. 4 (1992), pp. 493-500.

15. W.H. Alwan, F.M. Record and P.J.M. Openshaw, Phenotypic and functional characterization of $\mathrm{T}$ cell lines specific for individual respiratory syncytial virus proteins. J. Immunol. 150 (1993), pp. 5211-5218.

16. G.E. Hancock, D.J. Speelman, K. Heers, E. Bortell, J. Smith and C. Cosco, Generation of atypical pulmonary inflammatory responses in BALB/c mice after immunization with the native attachment $(\mathrm{G})$ glycoprotein of respiratory syncytial virus. J. Virol. 70 (1996), pp. 7783-7791.

17. A. Srikiatkhachorn and T.J. Braciale, Virus-specific memory and effector $\mathrm{T}$ lymphocytes exhibit different cytokine responses to antigens during experimental murine respiratory syncytial virus infection. J. Virol. 71 (1997), pp. 678-685.

18. A. Srikiatkhachorn and T.J. Braciale, Virus-specific CD8+ T lymphocytes downregulate $\mathrm{T}$ helper cell type 2 cytokine secretion and pulmonary eosinophilia during experimental murine respiratory syncytial virus infection. J. Exp. Med. 186 (1997), pp. 421-432.

19. G.P. Bembridge, R. Garcia-Beato, J.A. Lopez, J.A. Melero and G. Taylor, Subcellular site of expression and route of vaccination influence pulmonary eosinophilia following respiratory syncytial virus challenge in BALB/c mice sensitized to the attachment G protein. J. Immunol. 161 (1998), pp. 2473-2480.

20. T.R. Johnson, J.E. Johnson, S.R. Roberts, G.W. Wertz, R.A. Parker and B.S. Graham, Priming with secreted glycoprotein G of respiratory syncytial virus (RSV) augments interleukin-5 production and tissue eosinophilia after RSV challenge. J. Virol. 72 (1998), pp. 2871-2880.

21. T.R. Johnson and B.S. Graham, Secreted respiratory syncytial virus G glycoprotein induces interleukin-5 (IL-5), IL-13, and eosinophilia by an IL-4-independent mechanism. J. Virol. 73 (1999), pp. 8485-8495.

22. S. Gurunathan, D.M. Klinman and R.A. Seder, DNA vaccines: immunology, application, and optimization. Ann. Rev. Immunol. 18 (2000), pp. 927-974.

23. X. Li, S. Sambhara, C.X. Li, M. Ewasyshyn, M. Parrington, J. Caterini et al., Protection against respiratory syncytial virus infection by DNA immunization. J. Exp. Med. 188 (1998), pp. 681-688.
24. X. Martinez, X. Li, J. Kovarik, M. Klein, P.-H. Lambert and C.-A. Siegrist, Combining DNA and protein vaccines for early life immunization against respiratory syncytial virus in mice. Eur. J. Immunol. 29 (1999), pp. 3390-3400.

25. X. Li, S. Sambhara, C.X. Li, L. Ettorre, I. Switzer, G. Cates et al., Plasmid DNA encoding the respiratory syncytial virus $\mathrm{G}$ protein is a promising vaccine candidate. Virology 269 (2000), pp. 54-65.

26. M. Miller, J.Y. Cho, K.J. Baek, D. Castaneda, J. Nayar, M. Rodriquez et al., Plasmid DNA encoding the respiratory syncytial virus $G$ protein protects against RSV-induced airway hyperresponsiveness. Vaccine 20 (2002), pp. 3023-3033.

27. G.P. Bembridge, N. Rodriguez, R. Garcia-Beato, C. Nicolson, J.A. Melero and G. Taylor, DNA encoding the attachment $(G)$ or fusion $(F)$ protein of respiratory syncytial virus induces protection in the absence of pulmonary inflammation. J. Gen. Virol. 81 (2000), pp. 2519-2523.

28. R.S. Schrijver, J.P.M. Langedijk, G.M. Keil, W.G.J. Middel, M. Maris-Veldhuis, J.T. Van Oirschot et al., Immunization of cattle with a BHV1 vector vaccine or a DNA vaccine both coding for the G protein of BRSV. Vaccine 115 (1997), pp. 1908-1916.

29. T.R. Fuerst, E.G. Niles, F.W. Studier and B. Moss, Eukaryotic transient-expression system based on recombinant vaccinia virus that synthesizes bacteriophage T7 RNA polymerase. Proc. Natl. Acad. Sci. U.S.A. 83 (1986), pp. 8122-8126.

30. B. Brodersen and C. Kelling, Effect of concurrent experimentally induced bovine respiratory syncytial virus and bovine viral diarrhea virus infection on respiratory tract and enteric disease in calves. Am. J. Vet. Res. 59 (1998), pp. 1423-1430.

31. J.P.M. Langedijk, R.H. Meloen, G. Taylor, J.M. Furze and J.T. Van Oirschot, Antigenic structure of the central conserved region of protein $\mathrm{G}$ of bovine respiratory syncytial virus. J. Virol. 71 (1997), pp. 4055-4061.

32. R.A. Tripp, D. Moore, L. Jones, W. Sullender, J. Winter and L.J. Anderson, Respiratory syncytial virus G and/or SH protein alters Th1 cytokines, natural killer cells, and neutrophils responding to pulmonary infection in BALB/c mice. J. Virol. 73 (1999), pp. 7099-7107.

33. T.G. Kimman, F. Westenbrink, P.J. Straver, D. Van Zaane and B.E.C. Schreuder, Isotype-specific ELISAs for the detection of antibodies to bovine respiratory syncytial virus. Res. Vet. Sci. 43 (1987), pp. 180-187.

34. K. Muthumani, S. Kudchodkar, D. Zhang, M.L. Bagarazzi, J.J. Kim, J.D. Boyer et al., Issues for improving multiplasmid DNA vaccines for HIV-1. Vaccine 20 (2002), pp. 1999-2003.

35. A. Thermet, C. Rollier, F. Zoulin, C. Trepo and L. Cova, Progress in DNA vaccine for prophylaxis and therapy of hepatitis B. Vaccine 21 (2003), pp. 659-662.

36. R.A. Lerch, E.J. Stott and G.W. Wertz, Characterization of bovine respiratory syncytial virus proteins and mRNAs and generation of cDNA clones to the viral mRNAs. J. Virol. 63 (1989), pp. 833-840.

37. R.A. Lerch, K. Anderson and G.W. Wertz, Nucleotide sequence analysis and expression from recombinant vectors demonstrate that the attachment protein $\mathrm{G}$ of bovine respiratory syncytial virus is distinct from that of human respiratory syncytial virus. J. Virol. 64 (1990), pp. 5559-5569. 